\title{
The perceived needs-access gap for health services among persons with disabilities in a rural area within South Africa
}

Richard Vergunst, Leslie Swartz, Karl-Gerhard Hem, Arne Henning Eide, Hasheem Mannan, Malcolm MacLachlan, Gubela Mji \& Marguerite Schneider

To cite this article: Richard Vergunst, Leslie Swartz, Karl-Gerhard Hem, Arne Henning Eide, Hasheem Mannan, Malcolm MacLachlan, Gubela Mji \& Marguerite Schneider (2019) The perceived needs-access gap for health services among persons with disabilities in a rural area within South Africa, Disability and Rehabilitation, 41:22, 2676-2682, DOI: 10.1080/09638288.2018.1478001

To link to this article: https://doi.org/10.1080/09638288.2018.1478001

册 Published online: 29 Jun 2018.

Submit your article to this journal $\pi$

Џ Article views: 208

Q View related articles ๘

View Crossmark data \lceil 


\title{
The perceived needs-access gap for health services among persons with disabilities in a rural area within South Africa
}

\author{
Richard Vergunst ${ }^{a}$, Leslie Swartz ${ }^{a}$ D, Karl-Gerhard Hem ${ }^{b}$, Arne Henning Eide ${ }^{b, c}$, Hasheem Mannan ${ }^{d}$ (D), \\ Malcolm MacLachlan ${ }^{c, e, f}$, Gubela Mjic and Marguerite Schneider ${ }^{g}$ \\ ${ }^{a}$ Department of Psychology, Alan J Flisher Centre for Public Mental Health, Stellenbosch University, Stellenbosch, South Africa; ${ }^{b}$ Department of \\ Health, SINTEF Technology and Society, Oslo, Norway; ${ }^{C}$ Centre for Rehabilitation Studies, Stellenbosch University, Stellenbosch, South Africa; \\ ${ }^{\mathrm{d}}$ School of Nursing Midwifery \& Health Systems, Health Sciences Centre University College Dublin, Dublin, Ireland; ${ }^{\mathrm{e}}$ Assisting Living \& Learning

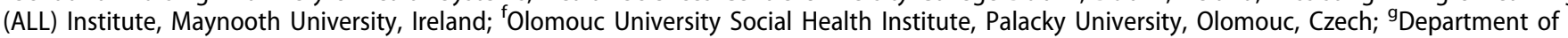 \\ Psychiatry \& Mental Health, Alan J Flisher Centre for Public Mental Health, University of Cape Town, Cape Town, South Africa
}

\begin{abstract}
Purpose: Health should be a universal phenomenon. However, little is known about the relationship between disability status and health issues - particularly in rural areas. This study looks at health issues of persons with disabilities in Madwaleni, a rural impoverished area in South Africa in 2011, and compares them to persons with no disabilities.

Materials and Methods: Standardized questionnaires were used in the survey to assess disability and health status. The sample comprised of 773 individuals -322 persons with disability and 451 comparisons (without disability) - covering 527 households. Children under the age of five were excluded from the sample. We used purposive sampling.

Results and Conclusion: This study found that persons with disabilities have poorer reported health outcomes than persons with no disabilities. There is also an association between disability severity and mental health issues as assessed by the GHQ-12. A significantly higher percentage of persons with disability did not get health care when needed. Persons with disabilities also have less favorable attitudes toward competence of health care workers. This study has shown greater health needs and less satisfaction with services, which strongly indicates insufficient access for persons with disabilities in a rural impoverished are within South Africa.

> IMPLICATIONS FOR REHABILITATION

- Persons with disabilities in rural South Africa have poorer reported health outcomes.

- Persons with disabilities have less favorable attitudes towards competence of health care workers in rural South Africa.

- Better access to health care for persons with disabilities is needed in rural South Africa.
\end{abstract}

\section{ARTICLE HISTORY}

Received 3 March 2017

Revised 29 April 2018

Accepted 14 May 2018

\section{KEYWORDS}

Rural health; disability; South Africa

\section{Introduction}

Although health should be a universal opportunity, this is not the case for many subsections of society [1], including persons with disabilities. Despite general agreement that health is not experienced equitably [2], there is relatively little research looking specifically at potential disparities between disability status and health [3]. This is especially relevant for impoverished communities where there is an association between poverty and increased need for health care [4]. Poverty in a community makes the right to health care a "distant dream" [5,p.1173]. This study looks at the relationship between disability and health in an impoverished rural context within South Africa.

\section{Disability and inequity in health}

The United Nation's [6] Convention on the Rights of Persons with Disabilities (UNCRPD), Article 25, states the necessity of care for persons with disabilities - it is not just a moral or universal obligation but a human right. The enjoyment of the highest attainable standard of health without discrimination on the basis of disability is highlighted in the Convention. Within South Africa, Section 27 of the Bill of Rights of the Constitution of South Africa 1996 affirms that everyone has the right to access to health care services and places an obligation on the state to take reasonable legislative and other measures within its available resources to achieve the progressive realization of this right.

Disability is an emerging field within public health [7]. International academic communities, clinical experts, and activists for persons with disabilities agree on the importance of health care services, and they argue that appropriate health care should be guaranteed for the entire population $[8,9]$. Persons with disabilities have specific and general health care needs. However, health care needs that are not met and that exacerbate health disparities are experienced disproportionately by persons with disabilities $[10,11]$. The World Report on Disability [3] as well as others [12] 
claim that doctors who lack training about disability frequently compromise patients' health care experiences and health outcomes. Emerson [13] identifies five key factors in the health inequalities of persons with disabilities which include poor access to health care, social determinants of poor health, intrinsic health vulnerabilities, communication difficulties and level of health literacy and lifestyle risk factors.

There is a growing body of evidence that persons with disabilities experience lower health status (both physically and psychologically) as well as excess burden of disease $[3,14,15]$, but still a broader recognition of these health disparities is needed [16]. As Krahn et al. [7] state, future research and policy directions should address health inequities for persons with disabilities. There is still little known about health care experiences among persons with and without disabilities [17] and this lack of knowledge about the actual dynamics, and experiences in obtaining health care is alluded to by Sharby et al. [18] when they state that persons with disabilities often require more and different interventions and accommodations to receive adequate health care.

The health of persons with disabilities in developing countries has not received enough attention in the literature [19]. Trani et al. [19,p.1483] found in their study in Sierra Leone that persons with disabilities "were more likely to report poorer health status" than persons with no disabilities. Mulumba et al. [20] found that participants in Uganda viewed their disability as a barrier to good health. This is despite some persons with disabilities having increased health needs [21,22]. Moodley and Ross [1] found in South Africa that persons with disabilities reported poorer health as well as higher incidence of communicable and non-communicable diseases.

\section{Disability and access to health services}

Lack of access to health care can affect an individual's health status, exacerbate existing health problems, and increase the risks for individuals developing new health problems that could have been prevented [23]. The relationship between disability and health care has received relatively little attention, despite it being important in terms of providing equal opportunities [15]. Persons with disabilities are among the most vulnerable groups of any population and are often excluded from mainstream health services [24]. WHO [3] state that persons with disability commonly need to be able to access appropriate mainstream health care and rehabilitation to a greater extent than persons without disability, because in addition to having the same health needs as others, they may have higher levels of need related to their impairments, health conditions, or the lifestyle consequences of these. It is, however, fully recognized that disability need not, and sometimes should not, be construed as a health problem [25].

While there is evidence in South Africa that suggests that policies are good, implementation may be failing persons with disabilities on these issues [26,27]. Maart et al. [27] go on to say that disability in South Africa is framed within a medical and welfare framework which results in the exclusion of persons with disabilities and their exposure to health access barriers. This is because of the strong emphasis on medical needs and a neglect on wider social needs resulting in the exclusion of persons with disabilities from mainstream society. The authors argue that government strategies should be focused on universal access for persons with disabilities, and placing disability within a human rights framework.

Despite the fact of further access needs, and a gap between needs and services offered, persons with disabilities constitute a marginalized group in health services research. Their experiences within the health care system are not well understood, and research-based health service improvement interventions rarely take the interests and particular needs of individuals with disability into account [28]. Only recently has a disability perspective been included in some health service research projects $[29,30]$.

\section{Disability and rurality}

According to the WHO [3], there is a higher prevalence of disability in rural areas compared to urban areas. Roughly four of every five persons with disabilities live in rural areas in developing countries [31,32]. There is scarce data on their health needs [33]. What little literature there is suggests that persons with disabilities in rural areas experience barriers to health care $[23,34,35]$ as well as low health status $[36,37]$.

There is little understanding of how poverty and disability interact in the rural context, where access to services and employment is often more limited [26]. According to Grut et al. [24,p.1], poor people with disabilities who live in poor rural societies "experience unique problems". The right to health care in rural areas is compromised by a number of health system and socioeconomic barriers [38]. The "triple vulnerability" - poverty, disability and rurality - has undergone limited research in terms of health status.

\section{Disability and health in rural communities in South Africa}

Only a few studies in rural South Africa [24,27,39-41] have specifically addressed disability and access to health care. Neille and Penn [39], in a qualitative study, found that barriers to service provision extend beyond physical obstacles and include a variety of sociocultural and sociopolitical barriers. Braathen et al. [40] describe the struggle to access health care for someone with a psychosocial impairment in a rural area. Grut et al. [24], also using a case study of a person with a disability in rural South Africa, show how people with disabilities who live in poverty-stricken areas experience multiple barriers. Maart et al. [27], however, found that persons with disabilities in the rural areas of the Eastern Cape perceived fewer barriers within their environment (with the exception of attitudes) than those residing in informal urban settlements in the Western Cape. The study by Jelsma et al. [41], on the other hand, looked at people with disabilities in rural Eastern Cape and concluded that a rural setting seemed to contribute to a worse perceived health-related quality of life.

While there has been research on access to health care, there has been a paucity of research assessing health status for persons with disabilities. This needs to be prioritized - especially in South African rural areas. Mechanisms leading to disparities in health status and the appropriateness of health services in impoverished rural populations needs to be understood in order to guide development towards equity in health.

This study aims to address this shortcoming and will look specifically at perceptions of health and associated health services among rural persons with disabilities and a systematically sampled comparison group.

\section{Methodology}

\section{Context of study}

This paper was part of a larger international project - the EquitAble Project (see www.sintef.no/Projectweb/Equitable). This international project was a four-year collaborative (2009-2012) research project comprised of researchers from Ireland, Norway, 
Sudan, Namibia, Malawi and South Africa looking at access to health care for vulnerable people in resource poor settings in Africa.

This paper is based on the findings in Madwaleni, one of the four settings used in South Africa. Data were collected in October-November 2011. The context of this study is the catchment area of Madwaleni Hospital, South Africa. The hospital is situated in a deeply rural and impoverished area of the Eastern Cape Province, $220 \mathrm{~km}$ up the coast from East London, $100 \mathrm{~km}$ from Mthatha, $30 \mathrm{~km}$ from Elliotdale and $16 \mathrm{~km}$ from the Wild Coast. The Madwaleni area is situated in the rolling hills of the Amatole District within the Mbashe Municipality. This rural area is defined by poor infrastructure, lack of basic service provision, low levels of literacy, high levels of unemployment, limited access to health care and education, high incidence of communicable diseases and high mortality rates [39].

\section{Sample of study}

The sample comprised of 773 individuals - 322 persons with disability and 451 controls (without disability) - covering 527 households. Children under the age of five were excluded from the sample. We used purposive sampling to first select four health centers surrounding the hospital, then random sampling to select the villages surrounding the health centers, and finally systematic sampling to select the households within the villages. Household questionnaires were administered with the head of the household to ascertain if the household had a person with a disability or not. Disability was defined by using the Washington Group Questions (WGQ) on Disability, wherein if an individual has "some difficulty" with two or more of the six questions, or has "a lot of difficulty" or is "unable to do" for one or more questions, they may be categorized as a person with activity or functional limitations, and categorized as "disabled". Further details of the sampling and categorization of participants have been reported by Eide et al. [42].

The Household questionnaire is a questionnaire administered to the head of the household in each household (after consent forms were completed). The Household questionnaire ascertained the composition of the household, that is, the members of the household, and whether or not they had a disability using the Washington Group (WG) Questions on disability. If a person with a disability was identified in the household, then that person completed consent forms and was also interviewed using the questionnaire for persons with disabilities. This questionnaire focused particularly on health and access to health care. If there were more than one person with a disability in a particular household, the person with the most severe disability was interviewed. This was ascertained by the disability rating scale in the household questionnaire where a higher total disability score according to the Washington Group method depicted more severe disability. This questionnaire focused particularly on health and access to health care. A third interview (after completion of consent forms) was carried out in the same household with a person without disability (in-house controls) matched to the person with disability by age (five year latitude either way) and gender using a Control questionnaire. This questionnaire is a shortened version of the one administered to individuals with disability. If no matched non-disabled control was found in the household, no control interview was carried out in that household. If the household did not have a person with disability living in the house then this household became a neighborhood control household. The head of the household would complete the Household questionnaire and a randomly selected person (using random tables) in the control household would complete the control questionnaire (neighborhood controls). The sample used in the study was not a representative sample of the population. Characteristics of the Head of Household in this sample is that $66 \%$ of households were headed by women with an average age of 56 years. The average age for men-headed households was 55 years. Of the 532 households, there were 112 only case households, 175 only control households and 245 case and control households.

\section{Instruments}

The questionnaires used in the survey were developed by a research team as part of a large international research project (Equitable) in four African countries. This study reports on parts of the questionnaires from the larger project that related to disability, health, and attitudes.

Interviews using three questionnaires were conducted in the study:

1. A household questionnaire.

2. A questionnaire for a person with a disability.

3. A control questionnaire for a person without disability.

This study used the Washington Group questions on disability [43] and the GHQ-12 questions [44] on mental health from the questionnaires from the larger study, as well as more general questions on physical health, mental health, "not getting health care" and "attitudes towards health care". The WG questions comprise 6 items measuring difficulty with six core functional domains (using a 4 point Likert scale including "No", "Some", "A lot" and "Unable" options). The GHQ-12 is a self-administered screening instrument with 12 items to ascertain mental health status of an individual with a yes/no response format.

In terms of ascertaining physical and mental health, there were two single questions asking about their respective health, using a scale from 1 (poor) to 4 (very good).

When ascertaining access to health care, there were two questions from the questionnaire - one asking a direct question about getting health care when needed, with a yes/no option, followed by a list of possible reasons why they did not get health care when they needed it.

Ascertaining attitudes towards health care was done through 9 items each with a four point Likert scale ranging from "strongly disagree" to "strongly agree".

The survey questionnaires, which were originally in English, were translated into isiXhosa and back-translated to make them more appropriate for the study site and its community members. The 17 data collectors/interviewers (all community health workers from the area) made use of cell-phone technology for data capturing and the data were then sent to a central data base where they were collated and analyzed. This method provides more accurate data than the traditional paper version, reduces missing data considerably, is easier to monitor locally and remotely, and has built-in quality checks [45].

\section{Statistical analysis}

The approach to data analysis for this paper included quantitative data analysis using descriptive and inferential statistics. We performed frequency and cross tabulation, comparing and contrasting the frequency of different phenomena between persons with disabilities and persons with no disabilities using Chi-squared tests, Analysis of Variance (ANOVA) and Regression Analysis.

Ethical approval for the overall study was obtained from the ethics committee of Stellenbosch University while ethics approval for doing research in Madwaleni was obtained from the Department of Health, Eastern Cape Province, South Africa. 
Table 1. Sample of individuals with and without disabilities.

\begin{tabular}{lrrr}
\hline Variables & $\begin{array}{r}\text { Nondisabled } \\
N, \%\end{array}$ & \multicolumn{1}{c}{$\begin{array}{c}\text { Disabled } \\
N, \%\end{array}$} & \multicolumn{1}{c}{$\begin{array}{c}\text { Total } \\
N, \%\end{array}$} \\
\hline Age $(N=773)$ & & & \\
$5-17$ years & $30,7.7$ & $19,5.0$ & $49,6.3$ \\
$18-60$ years & $330,84.2$ & $217,57.1$ & $547,70.9$ \\
$\quad 61+$ years & $32,8.2$ & $144,37.9$ & $176,22.8$ \\
Sex $(N=720)$ & & & \\
$\quad$ Male & $109,29.9$ & $100,28.2$ & $209,29.0$ \\
$\quad$ Female & $256,70.1$ & $255,71.8$ & $511,71.0$ \\
Level of education $(18+)(N=720)$ & & & \\
$\quad$ No formal education & $91,24.9$ & $206,58.0$ & $297,41.3$ \\
Less than primary school & $181,49.6$ & $113,31.8$ & $294,40.8$ \\
Primary school & $80,21.9$ & $27,7.6$ & $107,14.9$ \\
Secondary school & $12,3.3$ & $6,1.7$ & $18,2.5$ \\
Tertiary level education & $1,0.3$ & $3,0.8$ & $4,0.6$ \\
\hline
\end{tabular}

\section{Results}

The sample comprised $58.2 \%$ persons without disabilities (in house and neighborhood controls) and $41.8 \%$ with disabilities (cases). The majority in the sample were in the 18-60year age bracket, well over half were females, most respondents were currently married and most reported less than primary education. More individuals with disabilities were in the $61+$ years age range and fewer were between 18-60years $\left(\chi^{2}=96.92, \mathrm{df}=1\right.$, $p<0.001)$. Females were in the majority among both disabled and non-disabled (n.s.). More disabled than non-disabled had no formal education $\left(\chi^{2}=89.39, \mathrm{df}=1, p<0.001\right)$. Table 1 shows the main characteristics of the sample of individuals with and without disabilities.

\section{General physical and mental health}

Asked about their general physical and mental health on a scale of 1 (poor) to 4 (very good), persons with disability score lower than non-disabled on both (physical health: $\chi^{2}=102.36, \mathrm{df}=3$, $p<0.001$, mental health: $\left.\chi^{2}=75.44, \mathrm{df}=3, p<0.001\right)$. Still, more than half of individuals with disabilities (57.7\%) state that their physical health is either good or very good. While as many as $70.4 \%$ of persons with disabilities rate, their mental health to be either good or very good, the corresponding figure for non-disabled is as high as $92.0 \%$. Table 2 depicts the general physical health and mental health ratings discussed above.

Further to assessing subjects' mental health, questions from the General Health Questionnaire (GHQ-12) were also part of the individual survey. The GHQ-12 is a measure of psychological morbidity [44]. Analysis of the 12 individual items on the GHQ-12 showed eight of the items to be significantly different between the two groups and to the disadvantage of persons with disabilities. Also the four nonsignificant differences were to the disadvantage of persons with disabilities (Table 3). The largest difference in percentage points between disabled and nondisabled were for Feeling useful (34.8) and Not able to face problems (32.3).

For all single items in Table 3 (except with one item - "Lost much sleep") more persons with disabilities scored negative as compared to persons with no disabilities.

Scalability analysis resulted in alpha $=0.86$ for the 12 items which were subsequently added together to form a scale with range from $0-12$. A maximum score of 12 indicated the highest level of reported psychological problems and a minimum score of 0 indicating no psychological problems. Mean scale value was 4.21 for persons with disabilities and 2.71 for nondisabled $(\mathrm{F}=425.44, \mathrm{df}=1, p<0.001)$ and thus supports the general mental health rating discussed above.
Table 2. General physical health and mental health rating.

\begin{tabular}{lccccc}
\hline & \multicolumn{2}{c}{$\begin{array}{c}\text { General Physical } \\
\text { Health }(N=771)\end{array}$} & & \multicolumn{2}{c}{$\begin{array}{c}\text { General Mental } \\
\text { Health }(N=772)\end{array}$} \\
\cline { 2 - 3 } \cline { 5 - 6 } & No Disability & Disability & & No Disability & Disability \\
& $N, \%$ & $N, \%$ & & $N, \%$ & $N, \%$ \\
\hline Poor & $10,2.6$ & $66,17.4$ & & $8,1.8$ & $13,4.0$ \\
Not very good & $55,14.1$ & $95,25.0$ & & $28,6.2$ & $50,15.5$ \\
Good & $154,39.4$ & $156,41.1$ & & $229,50.9$ & $207,64.1$ \\
Very good & $172,44.0$ & $63,16.6$ & & $185,41.1$ & $53,16.4$ \\
\hline
\end{tabular}

Table 3. Comparisons between persons with and persons without disability in their psychological morbidity (GHQ-12) $(N=765-772)$.

\begin{tabular}{lccc}
\hline & No Disability & Disability \\
$N, \%$ & $N, \%$ & $\begin{array}{c}\text { Chi square } \\
\chi^{2}, \text { df, p }\end{array}$ \\
\hline Been able to concentrate & $329,83.9$ & $206,54.2$ & $80.10,1,<0.001$ \\
Lost much sleep & $117,29.8$ & $108,28.5$ & $0.17,1$, n.s. \\
Feeling useful & $308,78.6$ & $203,53.8$ & $52.70,1,<0.001$ \\
Been capable of making decisions & $323,82.6$ & $228,60.5$ & $46.38,1,<0.001$ \\
Felt constantly under strain & $101,25.8$ & $121,32.2$ & $3.76,1$, n.s. \\
Cannot overcome difficulties & $108,27.6$ & $131,34.7$ & $4.54,1,<0.05$ \\
Been able to enjoy day to day & $314,80.1$ & $234,61.9$ & $31.06,1,<0.001$ \\
$\quad$ & & & \\
activities & $322,82.1$ & $225,59.8$ & $45.58,1,<0.001$ \\
Been able to face problems & $100,25.5$ & $118,31.1$ & $3.01,1,<0.001$ \\
Been feeling unhappy & $88,22.6$ & $91,24.2$ & $0.29,1$, n.s. \\
Been losing confidence & $79,20.2$ & $84,22.5$ & $0.58,1$, n.s. \\
Been thinking you are worthlessness & $285,72.7$ & $234,61.9$ & $10.22,1,<0.01$ \\
Been feeling reasonably happy & & &
\end{tabular}

Table 4. Regression analysis of disability, age, sex and level of education on mental health (GHQ 12: anxiety and depression) $\left(N_{M}=702\right)$.

\begin{tabular}{|c|c|c|c|c|c|c|}
\hline \multirow[b]{2}{*}{ Variables } & \multicolumn{3}{|c|}{ Bivariate regression } & \multicolumn{3}{|c|}{ Multivariate regression } \\
\hline & Beta & $t$ & $p$ & Beta & $t$ & $p$ \\
\hline WG6 (disability) & 0.23 & 6.41 & $<0.001$ & 0.22 & 5.44 & $<0.001$ \\
\hline Age & 0.08 & 2.27 & $<0.05$ & -0.01 & -0.12 & n.s. \\
\hline Sex & 0.08 & 2.15 & $<0.05$ & 0.08 & 2.12 & $<0.05$ \\
\hline Level of education & -0.05 & -1.42 & 0.16 & -0.01 & -0.13 & n.s. \\
\hline
\end{tabular}

Adding the WG scale items produced a "disability scale" with range from 6 to 18, mean value 7.67, and standard deviation 2.27.

Bi-variate regressions of WG6 (disability), age, sex and level of education on mental health (GHQ 12) were carried out. Associations were significant for all except for level of education. This variable was, however, also included in the multivariate model due to level of significance being $<0.02$. The multivariate regression showed that mental health problems (GHQ 12) increased with severity of disability and were higher among females as compared to males. Age turned negative in the multivariate analyses due to its association with age, and no association was found between level of education and GHQ 12 (Table 4).

\section{Not getting health care}

A significantly higher percentage of persons with disabilities did not get health care the last time they needed it (direct question, yes $=1$, no $=2)(24.4 \%)$, compared to persons with no disabilities $(12.6 \%)\left(\chi^{2}=17.77, \mathrm{df}=1, p<0.001\right)$.

When considering reasons for not getting health care, cost and having no one to accompany oneself to go to health care were the only statistically significant factors that distinguished persons with no disabilities and persons with disabilities who did not get health care. Of persons with disabilities, $74.0 \%$ stated cost as a factor in not getting health care, while only $3.8 \%$ of non-disabled 
Table 5. Attitudes toward health care.

\begin{tabular}{lccc}
\hline & Non-disabled & Disabled & $\chi^{2}, \mathrm{df}, \mathrm{p}$ \\
\hline Health personnel at local clinic have Strongly disagree & 3.3 & 6.9 & $73.55,3,<0.001$ \\
appropriate competence $(N=771)$ Slightly disagree & 4.1 & 8.2 & \\
Slightly agree & 8.4 & 28.5 & \\
Strongly agree & 8.2 & 56.5 & \\
Health personnel at hospital have Strongly disagree & 2.3 & 4.8 & $69.72,3,<0.001$ \\
appropriate competence $(N=763)$ Slightly disagree & 2.8 & 4.3 & \\
Slightly agree & 6.4 & 27.2 & \\
Strongly agree & 88.5 & 63.7 & \\
Trust the treatment provided by Strongly disagree & 0.3 & 2.6 & $81.48,3,<0.001$ \\
personnel at local clinic $(N=772)$ Slightly disagree & 1.8 & 4.7 & \\
Slightly agree & 9.9 & 32.9 & \\
Slightly disagree & 88.0 & 59.7 & $73.56,3,<0.001$ \\
Trust the treatment provided Strongly disagree & 1.0 & 2.7 & \\
by personnel at the hospital $(N=769)$ Slightly disagree & 2.6 & 4.5 & \\
Slightly agree & 6.1 & 27.6 & \\
Strongly agree & 90.3 & 65.3 & $74.52,3,<0.001$ \\
People are received in a positive Strongly disagree & 1.3 & 3.4 & \\
manner at local clinic $(N=772)$ Slightly disagree & 3.1 & 3.2 & \\
Slightly agree & 7.7 & 30.8 & \\
Strongly agree & 88.0 & 62.6 & \\
People are received in a positive Strongly disagree & 2.0 & 3.0 & $54.40,3,<0.001$ \\
manner at the hospital $(N=762)$ Slightly disagree & 1.8 & 3.0 & \\
Slightly agree & 6.1 & 24.5 & \\
Strongly agree & 90.0 & 69.5 & \\
\hline
\end{tabular}

did the same $\left(\chi^{2}=66.33\right.$, df $\left.=1, p<0.001\right)$. On the other hand, $13.5 \%$ of nondisabled stated that they had no-one to accompany them, while the corresponding figure for persons with disabilities was $4.2 \%\left(\chi^{2}=4.24, \mathrm{df}=1, p<0.05\right)$.

\section{Attitudes toward health care}

The attitudes of health care users toward competence of health care personnel differ significantly between the two groups. Persons with disabilities have less favorable attitudes toward competence of health care workers, have less trust in the treatment and are more negative to the way they have been received by health personnel. For these three indicators, results are very similar for health clinic and the hospital. When this is said, it suffices to say that the overwhelming majority of both disabled and nondisabled provide positive responses to the competence, trust in treatment as well as the way they have been received. The difference between persons with and without disabilities lies in many respondents with disabilities tending to answer "agree" rather than "strongly agree" to the questions (Table 5).

Bi-variate regressions revealed no significant association between getting health care the last time needed and any of the attitude to health care variables in Table 5. However, GHQ 12 was positively associated with not getting health care $(\mathrm{OR}=1.17,95 \%$ $\mathrm{Cl}=1.13-1.20)$. This means that the likelihood of getting health care the last time needed was reduced with higher levels of GHQ/ mental problems.

\section{Discussion}

This study in a rural area within South Africa confirms earlier studies $[1,14]$ that persons with disabilities have poorer reported health outcomes than persons with no disabilities. Mental health problems increase with severity of disability and females had more mental health problems than males. Fewer individuals with disabilities get health care when they need it and have less positive attitudes to health personnel than non-disabled.
The results from this study confirm studies from other parts of the world. However, not many studies have looked at the issues of disability and health care in rural areas. In South Africa, 52\% of the total population and $75 \%$ of poor South Africans live in rural areas [46]. It is therefore important that disability research in South Africa includes looking into the context of rurality. The study has pointed to some factors that are key in explaining the current situation of health inequity, such as higher health needs and negative attitudes toward health personnel. Although the study does not enable analyses of causes of negative attitudes, we can assume that this at least partly is due to negative experiences. Shakespeare and Kleine [47] have for instance highlighted attitudinal barriers that prevent persons with disabilities from having their health needs met.

In terms of health issues for persons with disabilities in Madwaleni, we need to find recommendations and solutions. As Casey [48,p.179] states, accessing health care is a multi-level process. Interventions beyond health care access are required to meet health care needs of rural residents with disabilities [49]. A person with disability living in Madwaleni is not only about the "medical" issues but more importantly about social and inclusion issues. As Swartz and Watermeyer [50] state, the story of disability in South Africa, as well as in other countries, is about social oppression. There is still much to do before persons with disabilities in general, and those living in rural impoverished areas in particular, can be included in all parts of society including health care.

This study has clearly indicated insufficient access. According to Tomlinson et al. [9,p.1857], there is insufficient information available about effective interventions that work to improve the lives of people with disabilities, and the results call for "urgent attention to the issue of access to appropriate health care for people with disabilities especially in low-income and middleincome countries".

As Yee and Breslin [51] state, the removal of barriers would only be "a critical first step" toward achieving the broad public policy change needed for sustainable and equitable health care for persons with disabilities. According to these authors, such changes will only occur if the health care system recognizes that 
equitable health care - health care that addresses the different needs of different types of people - is a priority.

There are limitations with this study. Firstly, the study used self-reported measures to assess health. These measures may be biased. The participants, if they perceived the responses to be socially desirable, may have incorrectly reported the information [52]. The face-to-face interviews may have influenced the outcomes and, as Saulo et al. [53] point out, personal interaction affects the conversation. There were no independent confirmations by anybody of what the participants were reporting. This study only included reports from survey respondents and no formal assessments from health care staff or other informants. It was thus a subjective rating. Despite these limitations, which are common to many similar studies, particularly in the hard-to-reach rural areas we report from - this research also had several strengths. The relatively large sample size, the systematic approach to sampling and the use of a contextually relevant comparison group, allows our research to make a unique contribution to the literature. This paper is also supported by the parallel qualitative data that was part of the larger international equitable project. This qualitative data add depth to the statistical analysis of this paper $[23,54]$. These qualitative findings show that persons with disabilities face unique problems in accessing health care ranging from transport issues to attitudinal issues.

\section{Acknowledgements}

The authors thank all the participants in the study, the health authorities, and Jacqueline Gamble for technical assistance. All opinions expressed in this article are those of the authors alone and not those of any other person or organization.

\section{Disclosure statement}

No potential conflict of interest was reported by the authors.

\section{Funding}

This research was funded by the European Commission Framework Programme 7; Project Title: Enabling Universal and Equitable Access to Healthcare for Vulnerable People in Resource Poor Settings in Africa; Grant Agreement No. 223501.

\section{ORCID}

Leslie Swartz (D) http://orcid.org/0000-0003-1741-5897

Hasheem Mannan (D) http://orcid.org/0000-0001-6209-2586

\section{References}

[1] Moodley J, Ross E. Inequities in health outcomes and access to health care in South Africa: a comparison between persons with and without disabilities. Disabil Soc. 2015;30:630-644.

[2] Rowland M, Peterson-Besse J, Dobbertin K, et al. Health outcome disparities among subgroups of people with disabilities: A scoping review. Disabil Health J. 2014;7:136-150.

[3] World Health Organization. World report on disability. WHO Library Cataloguing-in-Publication Data; 2011.

[4] MacLachlan M, Swartz L. Disability and international development: towards inclusive global health. New York: Springer; 2009.
[5] Parnes P, Cameron D, Christie N, et al. Disability in lowincome countries: Issues and implications. Disabil Rehabil. 2009:31:1170-1180.

[6] United Nations. Convention on the Rights of persons with Disabilities. Geneva: United Nations; 2008. Available from: https://en.wikipedia.org/wiki/Convention_on_the_Rights_of_ Persons_with_Disabilities

[7] Krahn GL, Walker DK, Correa-De-Araujo R. Persons with disabilities as an unrecognised health disparity population. Am J Public Health. 2015;105:S198-S206.

[8] Clancy CM, Andresen EM. Meeting the health care needs of persons with disabilities. Milbank Q. 2002;80:381-391.

[9] Tomlinson M, Swartz L, Officer A, et al. Research priorities for health of people with disabilities: an expert opinion exercise. Lancet. 2009;374:1857-1862.

[10] Smith DL. Disparities in health care access for older adults with disabilities. Top Geriatr Rehabil. 2008;24:192-203.

[11] Pharr JR. Accommodations for patients with disabilities in primary care: a mixed methods study of practice administrators. Glob J Health Sci. 2014;6:23-32.

[12] lezzoni LI, Long-Bellil LM. Training physicians about caring for persons with disabilities: "Nothing about us without us!". Disabil Health J. 2012;5:136-139.

[13] Emerson E. Health status and health risks of the hidden majority of adults with intellectual. Disabilities. Intellect Dev Disabil. 2011;49:155-165.

[14] Walker C, Beck CR, Eccles R, et al. Health inequalities and access to health care for adults with learning disabilities in Lincolnshire. Br J Learn Disabil. 2014;44:16-23.

[15] Jeon B, Kwon S, Kim H. Health care utilisation by people with disabilities: A longitudinal analysis of the Korea Welfare Panel Study. Disabil Health J. 2015;8:353-362.

[16] Horner-Johnson W, Dobbertin K, Lee JC, et al. Disparities in health care access and receipt of preventive services by disability type: Analysis of the medical expenditure panel survey. Health Serv Res. 2014;49:1980-1999.

[17] De Vries Mc Clintock HF, Barg FK, Katz SP, et al. Health care experiences and perceptions among people with and without disabilities. Disabil Health J. 2016;9:74-82.

[18] Sharby M, Martire K, Iversen MD. Decreasing health disparities for people with disabilities through improved communication strategies and awareness. ljerph. 2015;12: 3301-3316.

[19] Trani J, Browne J, Kett $M$, et al. Access to health care, reproductive health and disability: a large scale survey in Sierra Leone. Soc Sci Med. 2011;73:1477-1489.

[20] Mulumba M, Nantaba J, Brolan CE, et al. Perceptions and experiences of access to public healthcare by people with disabilities and older people in Uganda. Int J Equity Health. 2014;13:76.

[21] Mannan H, MacLachlan M. Disability and health: a research agenda. Social Inclusion. 2013;1(1):37-45.

[22] Mji G, MacLachlan M, Melling-Williams N, et al. Realising the rights of disabled people in Africa: an introduction to the special issue. Disabil Rehabil. 2009;31(1):1-6.

[23] Van Rooy G, Amadhila EM, Mufune $P$, et al. Perceived barriers to accessing health services among people with disabilities in rural northern Namibia. Disabil Soc. 2012;27:761-775.

[24] Grut L, Mji G, Braathen SH, et al. Accessing community health services: challenges faced by poor people with disabilities in a rural community in South Africa. Ajod. 2012;1:19.

[25] Author, Author. 2013. 
[26] Graham L, Moodley J, Ismail Z, et al. Poverty and disability in South Africa. Research report. Centre for Social Development in Africa. Johannesburg: University of Johannesburg; 2014.

[27] Maart S, Eide $\mathrm{AH}$, Jelsma J, et al. Environmental barriers experienced by urban and rural disabled people in South Africa. Disabil Soc. 2007;22(4):357-369.

[28] Scheer J, Kroll T, Neri MT, et al. Access barriers for persons with disabilities - The consumer's perspective. J Disabil Policy Stud. 2003;13:221-230.

[29] Davis MH, O'Brien E. Profile of persons with disabilities in Medicare and Medicaid. Health Care Financ Rev. 1996;17:179-211.

[30] Gold M, Nelson L, Brown R, et al. Disabled medicare beneficiaries in HMOs. Health Aff (Millwood). 1997;16:149-162.

[31] UN Enable. World Programme of Action Concerning Disabled Persons. Geneva: United Nations; 2006. Available from: http://www.un.org/esa/socdev/enable/diswpa04.htm

[32] Marks D. Disability: Controversial debate and psychosocial perspectives. London: Routledge; 1999.

[33] Lishner DM, Richardson $M$, Levine $P$, et al. Access to primary health care among persons with disabilities in rural areas: A summary of the literature. J Rural Health. 1996;12:45-53.

[34] Hamdan M, Al-Akhras N. House-to-house survey of disabilities in rural communities in the north of the West Bank. East Mediterr Health J. 2009;15:1496-1503.

[35] Ahmad M. Health care access and barriers for the physically disabled in rural Punjab, Pakistan. Int J Sociol Soc Policy. 2013;33:246-260.

[36] de Pedro-Cuesta J, Comín Comín M, Virués-Ortega J, et al. ICF-Based disability survey in a rural population of adults and older adults living in Cinco Villas. Northeastern Spain: Design, Methods and Population Characteristics. Neuroepidemiology 2010;73:72-82.

[37] Rohrer JE, Merry SP, Thacher TD, et al. Self-assessed disability and self-rated health among rural villagers in Peru: a brief report. J Rural Health. 2010;26:294-298.

[38] Gaede $B$, Versteeg $M$. The state of the right to health in rural South Africa. In: Padarath A, English R, editors. South African Health Review 2011. Durban: Health Systems Trust; 2011.

[39] Neille J, Penn C. Beyond physical access: a qualitative analysis into the barriers to policy implementation and service provision experienced by persons with disabilities living in a rural context. Rural Remote Health. 2015;15:3332. Available from: http://www.rrh.org.au
[40] Braathen SH, Vergunst R, Mji G, et al. Understanding the local context for the application of global mental health: a rural South African experience. Int Health. 2013;5:38-42.

[41] Jelsma J, Maart S, Eide A, et al. The determinants of healthrelated quality of life in urban and rural isi-Xhosa-speaking people with disabilities. Int J Rehabil Res. 2007;30(2):119-126.

[42] Eide $\mathrm{AH}$, Mannan $\mathrm{H}$, Khogali $\mathrm{M}$, et al. Perceived barriers for accessing health services among individuals with disability in four African countries. PLoS One. 2015;10(5):e0125915.

[43] Washington Group on Disability Statistics. Rationale for the Short Set; 2010. Available from: http://www.cdc.gov/nchs/ washington_group/wg_rationale.htm.

[44] Hankins $M$. The reliability of the twelve-item general health questionnaire (GHQ-12) under realistic assumptions. BMC Public Health. 2008;8:

[45] Tomlinson $M$, Solomon $W$, Singh $Y$, et al. The use of mobile phones as a data collection tool: a report from a household survey in South Africa. BMC Med Inform Decis Mak. 2009;9:51.

[46] Reid SJ. Rural health and transformation in South Africa. S Afr Med J. 2006;96:676-677.

[47] Shakespeare T, Kleine I. Educating health professionals about disability. A Review of Interventions. HSCE. 2013;2:1-18.

[48] Casey R. Disability and unmet health care needs in Canada: A longitudinal analysis. Disabil. Health J. 2015;8:173-181.

[49] lezzoni LI, Killeen MB, O'Day BL. Rural residents with disabilities confront substantial barriers to obtaining primary care. Health Serv Res. 2006;41:1258-1275.

[50] Swartz L, Watermeyer B. Introduction and overview. In: Watermeyer B, Swartz L, Lorenzo T, Schneider M, Priestley $M$, editors. Disability and social change - a South African agenda. Cape Town: HSRC; 2006. p. 1-6.

[51] Yee S, Breslin ML. Achieving accessible health care for people with disabilities: Why the ADA is only part of the solution. Disabil Health J. 2010;3:253-261.

[52] Adams AS, Soumerai SB, Lomas J, et al. Evidence of selfreport bias in assessing adherence to guidelines. Int J Qual Health Care. 1999;11:187.

[53] Saulo B, Walakira E, Darj E. Access to healthcare for disabled persons. How are blind people reached by HIV services? Sex Reprod Healthc. 2012;3:49-53.

[54] Vergunst R, Swartz L, Mji G, et al. "You must carry your wheelchair" - Barriers to accessing health care in a South African rural area. Glob Health Action. 2015;8:29003. 